\title{
Analysis of Factors Affecting the Hidden Costs of Construction Projects Factor Analysis
}

\author{
Shuyang Liu ${ }^{1}$, Jiaye $\mathrm{Wu}^{2 *}$, Yue Yue1, Yingqian Zhang ${ }^{3}$ \\ ${ }^{1}$ School of Management of Sichuan University of Science \& Engineering, Zigong, China \\ ${ }^{2}$ Sichuan Shengtuo Testing Technology Co., LTD., Zigong, China \\ ${ }^{3}$ School of Civil Engineering of Sichuan University of Science \& Engineering, Zigong, China \\ Email: ‘931074431@qq.com
}

How to cite this paper: Liu, S.Y., Wu, J.Y., Yue, Y. and Zhang, Y.Q. (2019) Analysis of Factors Affecting the Hidden Costs of Construction Projects Factor Analysis. Open Access Library Journal, 6: e5665. https://doi.org/10.4236/oalib.1105665

Received: August 6, 2019

Accepted: August 19, 2019

Published: August 22, 2019

Copyright ( 2019 by author(s) and Open Access Library Inc.

This work is licensed under the Creative

Commons Attribution International

License (CC BY 4.0).

http://creativecommons.org/licenses/by/4.0/

\section{Open Access}

\begin{abstract}
Since the hidden costs of construction projects are subtle and strong, difficult to quantify, it has not yet resulted in completing research system. This paper analyzes the literature to identify the concepts and forms of hidden costs, then summarizes the factors affecting the construction of 20 projects in hidden costs. Factor analysis extracted six comprehensive factor variables to represent the most influential factors, propose appropriate measures to control construction projects of hidden costs, and lay the foundation for further quantifying the hidden costs for these factors.
\end{abstract}

\section{Subject Areas \\ Engineering Management}

\section{Keywords}

Factor Analysis, Construction Project, Hidden Cost, Common Factor Variable

\section{Introduction}

In recent years, with the continuous expansion of the scale of China's construction industry, some problems of construction companies have gradually emerged, and the more prominent is the issue of cost management. The cost of a construction project includes not only the explicit costs on the financial statements, but also the hidden costs that are hard to quantify. The hidden cost is the same as the categorical cost, which is a part of the total cost of the project, which seriously affects the development of construction enterprises [1]. If you do not control hidden costs, it will cause the company to lose a lot of benefits. Therefore, only 
by taking the hidden costs seriously, fully understanding and effectively controlling the hidden costs can get the maximum benefit.

\section{Identification of Factors Affecting the Hidden Cost of Construction Engineering Projects}

\subsection{Determination of the Influencing Factors of Hidden Costs of Construction Projects}

The influencing factors of hidden costs of construction projects are many and complex. In order to fully identify various influencing factors, it is necessary in order to classify them in a specific way [2]. From the perspective of the entire project, people are the main body of management and belong to the various participants of the project, which is the main source of hidden costs of the project. Therefore, the main participants of the project are divided into the owner, the designer and the construction party, and through the consultation of relevant literature, the construction phase of the project is determined through consultation and interviews with professionals in the design, construction, construction and universities. There are 20 influencing factors of hidden costs, as showing in Table 1.

Table 1. Table of factors affecting hidden costs of construction projects.

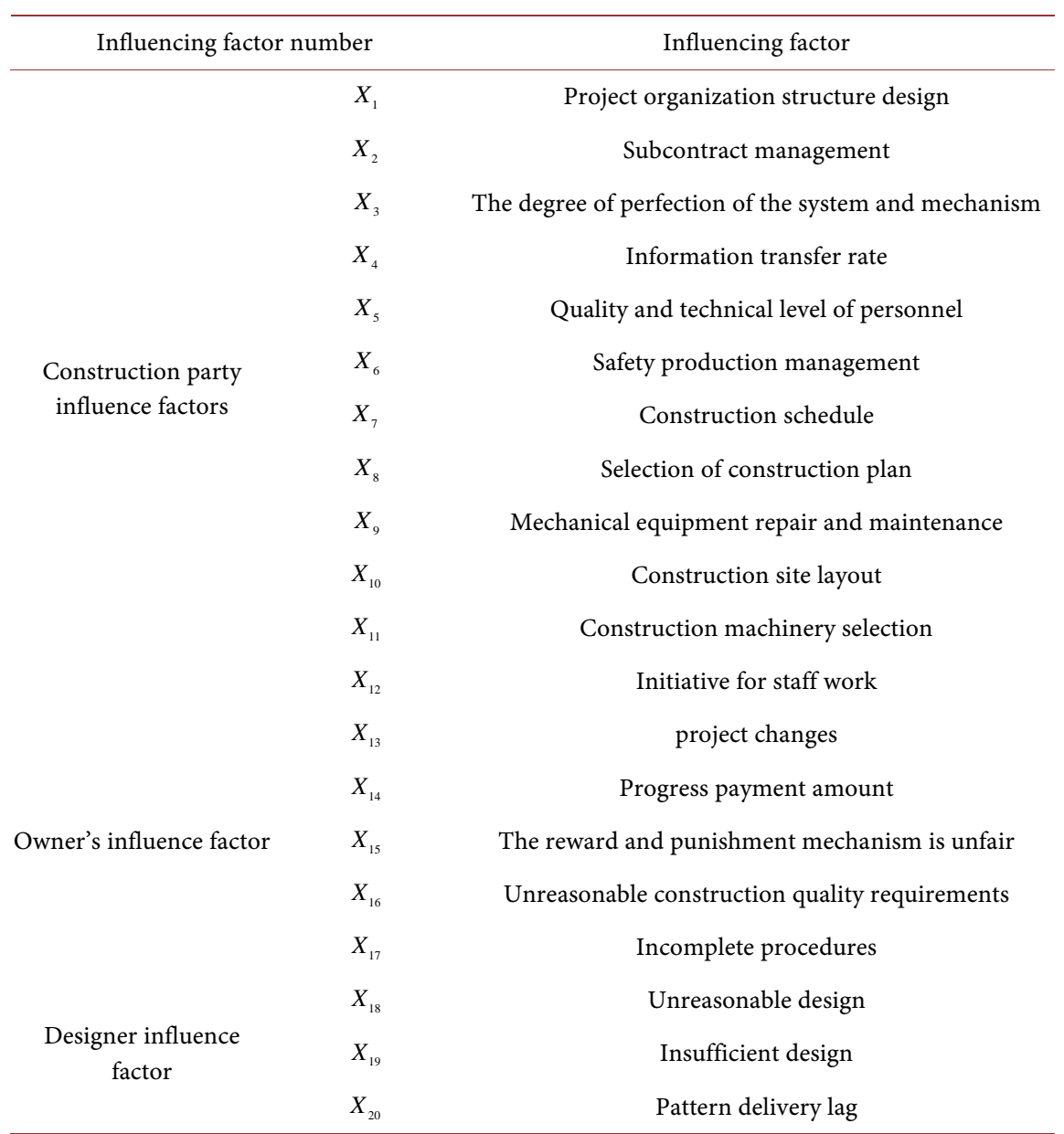




\subsection{Expert Scoring Method and Sample Data Inspection}

The data of quantitative analysis of influencing factors are collected by experts. The designed questionnaire mainly includes two parts: basic information and metrics. The basic information is the personal information of the experts, such as the work unit, the number of years of employment, professional titles, etc. It is used to score the influence degree of the influencing factors and record the relevant suggestions given by the respondents. The questionnaire is measured by the Liken 5 subscale, and 1 - 5 represents the degree of influence from low to high [3], that is, "no impact", "slightly affected", "influenced in general", "large impact", "very influential" "Large", invited experts in the construction industry to judge the importance of the influencing factors of hidden costs of engineering projects according to their theoretical level and practical experience. The questionnaire was made available through interviews and emails. A total of 100 questionnaires were distributed and 98 valid questionnaires were sent back.

Because the experience of survey experts is different, and the influencing factors are altered in different engineering projects. The experts participating in the survey will also have a bias in understanding the importance of the influencing factors. In order to ensure that the sample data of the survey meet the reliability requirements, it is necessary in order to verify the validity of the consistency. Using the SPSS statistical analysis software, the Cronbach $\alpha$ coefficient was selected as the calculation test method, and the reliability test results are presented in Table 2.

As can be seen from Table 2, the Cronbach $\alpha$ coefficient of the reliable risk analysis of the questionnaire data is 0.866 , and the standardized Cronbach $\alpha$ coefficient is 0.916 , both of which are greater than 0.8 , indicating that the questionnaire is included in the questionnaire. Measures of the 22 influencing factors are effective and credible and can meet the needs of statistical analysis.

\section{Analysis of Factors Affecting the Hidden Costs of Construction Projects Factor Analysis}

Factor analysis is the study of how lost at a minimum the amount of information extracted several comprehensive factors representative variables from a number of original variables, and how to make it multivariate data analysis methods with a strong interpretability [4]. Factor analysis is utilized to analyze and evaluate the metric data of the hidden cost of the project, and several common factors affecting the hidden cost of the project can be obtained. When the project implicit cost control is carried out, it is easier to understand. Live the principal contradiction of the problem, thereby improving decision-making efficiency and controlling performance.

Table 2. Reliability statistics.

\begin{tabular}{ccc}
\hline Cronbach's Alpha & Cronbach's Alpha is based on standardized items & Number of items \\
\hline 0.866 & 0.916 & 22 \\
\hline
\end{tabular}




\subsection{Applicability of Factor Analysis}

Statistical analysis of sample data using factor analysis begins with a suitability test for factor analysis of influencing factor variables, including KMO (Kaiser-Meyer-Olkin) test and Bartlett sphericity variable partiality test. To examine whether the factor variables are suitable for factor analysis, the test results are shown in Table 3.

According to the statistical principle of KMO test and Bartlett sphericity test [5], the factor analysis applicability test of 22 influential factor variable sample data shows that the value of $\mathrm{KMO}$ is $0.677>0.5$, which satisfies the reference standard given by the statistician Kaiser. Explain that the sample data is suitable for factor analysis; in addition, the correlation probability value obtained by the Bartlett sphericity test is less than 0.05 , so the rejection of the statistical matrix is the original hypothesis of the identity matrix, and also indicates that there is a correlation between the influential factors. Perform factor analysis.

\subsection{Extract Common Factor}

Using the principal component analysis method, the eigenvalues of the correlation matrix of the influencing factor variables is obtained. The results are shown in Table 4.

Factor analysis generally selects factors with eigenvalues greater than 1 [6]. It can be seen from Table 4 that the eigenvalues of the first six factors are greater than 1 , and should be extracted. And the percentage of variance explained by the accumulation of the first six factors is $81.012 \%$, indicating that most of the information in the original factor variables can be reflected by these six factors.

\subsection{Factor Load Analysis and Public Factor Naming}

In order to obtain professional actors, it is necessary to rotate the common factors so that the information difference of each factor is expanded as much as possible [7]. The variance of the correlation matrix of the influencing factor variable is maximized by orthogonal rotation (Varimax). See Table 5 for the factor load after rotation and Table 6 for the factor load matrix.

If the load of the factor in the matrix is greater than 0.5 , the variable is considered to be very significant in the common factor [8]. Therefore, in the factor load matrix after rotation, find out the factor variables that have a greater influence on each common factor, synthesize their actual meanings and characteristics, and name the common factors, see Table 7.

Table 3. KMO and Bartlett test.

\begin{tabular}{lcc}
\hline \multicolumn{2}{c}{ Sampling sufficient Kaiser-Meyer-Olkin metric } & 0.677 \\
\hline \multirow{3}{*}{ Bartlett's sphericity test } & Approximate Chi-Square & 3576.398 \\
& Degree of freedom & 120 \\
& Significant level & 0.000 \\
\hline
\end{tabular}


Table 4. Principal component analysis table.

\begin{tabular}{|c|c|c|c|c|c|c|}
\hline \multirow{2}{*}{ Composition } & \multicolumn{3}{|c|}{$\begin{array}{l}\text { Initial } \\
\text { eigenvalue }\end{array}$} & \multicolumn{3}{|c|}{$\begin{array}{l}\text { Extracting the sum } \\
\text { of squared loads }\end{array}$} \\
\hline & Total & $\begin{array}{l}\text { Percentage of } \\
\text { variance }\end{array}$ & Cumulative \% & Total & $\begin{array}{c}\text { Percentage of } \\
\text { variance }\end{array}$ & Cumulative \% \\
\hline 1 & 4.891 & 24.317 & 24.317 & 3.891 & 24.317 & 24.317 \\
\hline 2 & 3.163 & 16.770 & 41.087 & 3.163 & 19.770 & 41.087 \\
\hline 3 & 2.866 & 14.915 & 56.002 & 2.866 & 17.915 & 56.002 \\
\hline 4 & 2.226 & 12.910 & 68.912 & 2.226 & 13.910 & 68.912 \\
\hline 5 & 1.482 & 7.264 & 76.176 & 1.482 & 9.264 & 76.176 \\
\hline 6 & 1.224 & 4.836 & 81.012 & 1.224 & 4.836 & 81.012 \\
\hline 7 & 0.852 & 3.886 & 84.898 & & & \\
\hline 8 & 0.602 & 3.356 & 88.254 & & & \\
\hline 9 & 0.521 & 3.157 & 91.411 & & & \\
\hline 10 & 0.433 & 2.807 & 94.218 & & & \\
\hline 11 & 0.233 & 2.208 & 95.977 & & & \\
\hline 12 & 0.181 & 1.739 & 96.108 & & & \\
\hline 13 & 0.118 & 0.739 & 97.847 & & & \\
\hline 14 & 0.106 & 0.666 & 98.512 & & & \\
\hline 15 & 0.090 & 0.563 & 99.075 & & & \\
\hline 16 & 0.049 & 0.309 & 99.384 & & & \\
\hline 17 & 0.043 & 0.269 & 99.653 & & & \\
\hline 18 & 0.038 & 0.152 & 99.805 & & & \\
\hline 19 & 0.022 & 0.111 & 99.916 & & & \\
\hline 20 & 0.018 & 0.084 & 100.000 & & & \\
\hline
\end{tabular}

Table 5. Rotated factor load table.

\begin{tabular}{cccc}
\hline & \multicolumn{3}{c}{ Sum of squared rotational loads } \\
\cline { 2 - 4 } Composition & Total & $\begin{array}{c}\text { Percentage } \\
\text { of variance }\end{array}$ & Cumulative \% \\
\hline 1 & 3.427 & 21.421 & 21.421 \\
2 & 2.841 & 14.757 & 36.178 \\
3 & 2.792 & 14.451 & 50.629 \\
4 & 2.448 & 13.300 & 63.929 \\
5 & 2.120 & 9.248 & 73.177 \\
6 & 1.850 & 7.835 & 81.012 \\
\hline
\end{tabular}


Table 6. Rotating factor load matrix.

\begin{tabular}{|c|c|c|c|c|c|c|}
\hline \multirow{2}{*}{$\begin{array}{c}\text { Factor } \\
\text { variable }\end{array}$} & \multicolumn{6}{|c|}{ Composition } \\
\hline & 1 & 2 & 3 & 4 & 5 & 6 \\
\hline$X_{1}$ & 0.052 & -0.098 & 0.107 & 0.066 & 0.857 & -0.003 \\
\hline$X_{2}$ & -0.172 & 0.658 & 0.073 & 0.019 & 0.214 & -0.204 \\
\hline$X_{3}$ & 0.153 & 0.393 & -0.158 & 0.530 & 0.130 & -0.143 \\
\hline$X_{4}$ & -0.063 & 0.078 & 0.717 & -0.027 & 0.030 & 0.273 \\
\hline$X_{5}$ & -0.036 & 0.477 & -0.030 & 0.096 & 0.260 & 0.302 \\
\hline$X_{6}$ & -0.024 & 0.577 & 0.105 & 0.218 & 0.253 & -0.172 \\
\hline$X_{7}$ & 0.090 & 0.150 & 0.015 & 0.792 & -0.177 & 0.120 \\
\hline$X_{8}$ & 0.567 & 0.089 & 0.063 & -0.170 & -0.034 & 0.278 \\
\hline$X_{9}$ & 0.684 & 0.026 & -0.054 & 0.213 & 0.022 & 0.095 \\
\hline$X_{10}$ & 0.598 & 0.156 & -0.295 & -0.078 & 0.369 & 0.058 \\
\hline$X_{11}$ & 0.556 & 0.240 & -0.144 & 0.090 & 0.388 & -0.051 \\
\hline$X_{12}$ & -0.118 & 0.097 & 0.546 & 0.445 & 0.103 & -0.132 \\
\hline$X_{13}$ & -0.047 & 0.674 & -0.065 & 0.193 & -0.100 & 0.432 \\
\hline$X_{14}$ & 0.565 & 0.101 & -0.012 & -0.036 & 0.023 & 0.347 \\
\hline$X_{15}$ & 0.412 & 0.076 & 0.040 & -0.083 & -0.036 & 0.615 \\
\hline$X_{16}$ & 0.142 & 0.796 & -0.054 & -0.112 & 0.005 & 0.145 \\
\hline$X_{17}$ & 0.326 & 0.635 & -0.078 & -0.054 & 0.030 & 0.046 \\
\hline$X_{18}$ & 0.396 & 0.229 & 0.055 & 0.541 & -0.354 & 0.205 \\
\hline$X_{19}$ & 0.837 & -0.017 & 0.187 & 0.023 & -0.042 & 0.123 \\
\hline$X_{20}$ & 0.669 & 0.095 & 0.314 & -0.021 & 0.129 & -0.011 \\
\hline
\end{tabular}

Table 7. KMO and Bartlett test.

\begin{tabular}{ccc}
\hline Common factor number & Influence factor variable & Public factor naming \\
\hline$Y_{1}$ & $X_{19}, X_{9}, X_{20}, X_{15}, X_{10}, X_{8}, X_{14}, X_{11}$ & Participant skill level \\
$Y_{2}$ & $X_{16}, X_{13}, X_{2}, X_{17}, X_{6}$ & Construction management \\
$Y_{3}$ & $X_{4}, X_{12}, X_{20}$ & Level of participation \\
$Y_{4}$ & $X_{7}, X_{18}, X_{3}$ & Pre-construction design plan \\
$Y_{5}$ & $X_{1}$ & Project organization structure design \\
$Y_{6}$ & $X_{15}$ & Progress payment \\
\hline
\end{tabular}

Measures to control the hidden costs of construction projects usually include contract measures, technical measures, economic measures, and management measures. The following is a combination of six common factors to make recommendations for controlling the hidden costs of construction projects. The technological level of the participants is the most important thing factor. From the perspective of management measures, active control of hidden costs, increase 
of preventive input, increases the level of hidden cost management, thereby reducing the probability of unnecessary costs, and ultimately achieves control of construction projects. The purpose of the cost of sex. From the perspective of construction management, construction companies can adopt certain management measures to become passively accepted as operational control. From the perspective of the level of cooperation of the participating parties, construction enterprises can adopt contractual measures to transfer some uncontrollable hidden costs through contract, so as to reduce the hidden costs of construction projects. Construction enterprises can reduce the incidence of pre-construction design planning and project organization structure design on the hidden costs of construction projects through contractual measures and economic measures. Construction enterprises should adopt technical measures to fully consider the impact of the regional economy on hidden costs and formulate corresponding pre-control strategies. The introduction of six common factors allows construction companies to more clearly grasp the key points affecting cost control, and the contract, technology, economic and management measures proposed by combining six factors help construction enterprises to better improve hidden cost management. Reduce hidden costs.

\section{Conclusions}

From the perspective of the project participants, the influencing factors of the hidden costs of the project are summarized, and six common factors are extracted to provide decision makers with targeted control measures.

According to the actual situation of different projects, different weights are given to the extracted common factor variables, which help decision makers to evaluate the control of hidden costs of construction projects.

Although this paper conducts a preliminary quantitative analysis of the influencing factors of the hidden costs of construction projects, the interrelationship between the various influencing factors still needs in-depth exploration and research.

\section{Conflicts of Interest}

The authors declare no conflicts of interest regarding the publication of this paper.

\section{References}

[1] Yang, J.L. (2008) Research on Hidden Cost Control of Construction Enterprise Projects. Beijing JiaoTong University, Beijing.

[2] Gu, T.Y. (2011) Research on the Influencing Factors and Control Strategies of Hidden Costs in the Construction Phase of Construction Projects. Xi'an University of Architecture and Technology, Xi'an.

[3] Sun, C.L., Song, H., Yan, X.F., et al. (2013) Construction of the Construction Project Manager's Ability Index System. Forecast, 1, 72-76.

[4] Du, Y.B. (2009) Research on Performance Evaluation of China's Real Estate Listed 
Companies Based on Factor Analysis. Chongqing University, Chongqing.

[5] Zhang, W.Z. and Zhong, Y.F. (2013) IBM SPSS Data Analysis and Mining Case Study Essence. Tsinghua University Press, Beijing, 229-232.

[6] Sun, X. (2009) An Application of Factor Analysis Method in Life Quality Assessment of Urban Residents in Jiangsu Province. Nanjing University of Aeronautics and Astronautics, Nanjing.

[7] Zhang, S.L. and Li, P. (2011) An Empirical Study on Risk Factors of Architectural Engineering Design Based on Factor Analysis. China Safety Science Journal, 3, 131-138.

[8] Reise, S.P., Waller, N.G. and Comery, A.L. (2000) Factor Analysis and Scale Revision. Psychological Assessment, 12, 287-297.

https://doi.org/10.1037/1040-3590.12.3.287 